\title{
China health technology and stringency containment measures during COVID-19 pandemic: A discussion of first and second wave of COVID-19
}

\author{
Hafiz Syed Mohsin Abbas ${ }^{1}\left[\right.$ (]) Xiaodong Xu ${ }^{1} \cdot$ Chunxia Sun $^{1}$
}

Received: 18 November 2020 / Accepted: 1 January 2021 / Published online: 14 January 2021

( ) IUPESM and Springer-Verlag GmbH Germany, part of Springer Nature 2021

\begin{abstract}
This short communication highlights the Chinese health and stringency containment measures in the background of technology deployment and development during the COVID-19 pandemic in China. By achieving the study objective, this communication takes Health Containment Index and Stringency Response Index as independent variables and COVID-19 new confirmed cases as the dependent variable in the period January to October 2020. Applying simple linear regression analysis and china's technological revolution shows that china's 5G technology in the containment policies and medical support played a vital role in combat the first wave of COVID-19. These measures have remained sustainable and consistent, which made China resumption the economy and state development affairs. Furthermore, the second wave of COVID-19 was also under control due to sustainable policy enforcement during the first wave. In strengthening the health system and e-government system, China's 6G successful invention will make china's institutional structure to the next level and sustainable in combating future calamities and projected forthcoming waves of COVID-19.
\end{abstract}

Keywords COVID-19 $5 \mathrm{G}$ and $6 \mathrm{G} \cdot$ Health containment $\cdot$ Stringency response $\cdot$ China

\section{Introduction}

China was the first victim of the COVID-19 pandemic in December 2019; since then, COVID-19 has been extinguishing global health and emergency measures (Hasan 2020; Ashraf 2020). China's government has made various policy initiatives and enforcement in controlling the COVID-19 situation, and it succeeded; however, the pandemic is not over yet (The State Council of China 2020; Maragakis 2020). The world is indifferent

This article is part of the COVID-19 Health Technology: Design, Regulation, Management, Assessment

Hafiz Syed Mohsin Abbas

abbas_hsm@hust.edu.cn; mohsin01@163.com

Professor Xiaodong Xu

xiaodong-xu@hust.edu.cn

Associate Professor Chunxia Sun

chunxia222@126.com

1 College of Public Administration (CPA), Huazhong University of Science and Technology (HUST) Main Campus, Wuhan, P.R. China about whether the COVID-19 first wave has ended, and the second wave has not started yet. China has opened its industry and rehabilitated the economic operations in April 2020, and now it is boosting the economy at its previous pace before the COVID-19 pandemic. It has evidence that China has made aggressive and innovative health containment measures, making it possible to control COVID-19 (International Monetary Fund 2020) (World Health Organization 2020; Hale et al. 2020).

\section{Chinese containment during first COVID-19 wave}

China has made various healthcare strategy measures and policy initiatives during the pandemic, e.g., 5G (Fifth $/ 5^{\text {th }}$ Generation) technology launching, BIM (Building Infrastructure Management) usage, co-governance, and sharing employment concepts during COVID-19, an excellent illustration of public and private collaboration (Brende and Morhard 2020; CBI 2020; Sengyee 2020). In combating the first wave of COVID19, China has used 5G technology in the healthcare system (World Economic Forum 2020). China introduced a Health 
Fig. 1 HC and COVID-19 situation during the first phase of COVID-19 in China. Source: Hale et al. 2020 and Humanitarian Data Exchange 2020

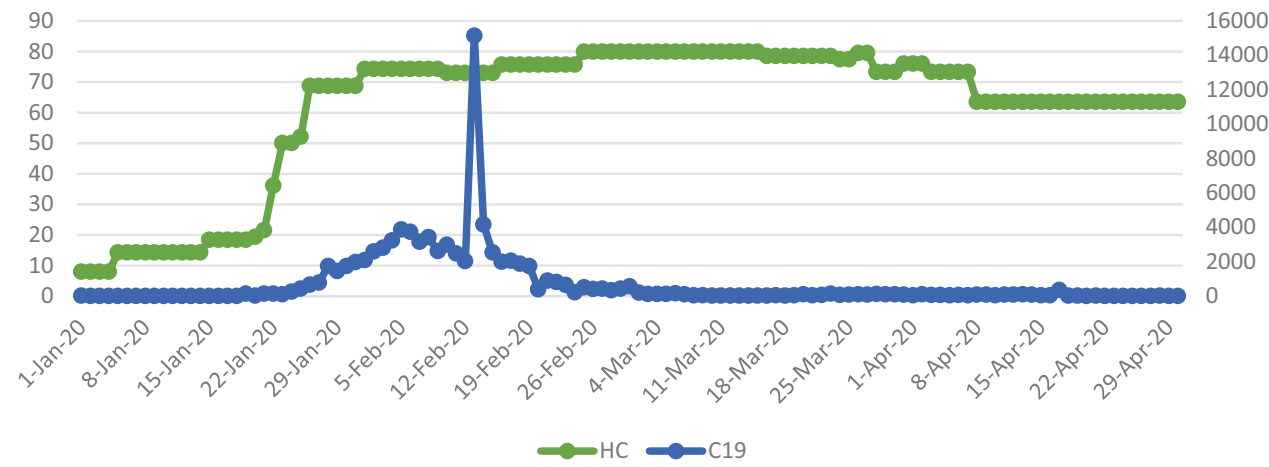

application and registered the citizens at rapid speed. This application provides the updated COVID-19 situation in China and the rest of the world. Moreover, it also shares the citizen's health status or registered person, which will support $\mathrm{him} / \mathrm{her}$ traveling and attending the country's events $\mathrm{Wu}$ et al. 2020; Smith 2020; National Health Commission, China 2020). Furthermore, healthcare professionals have used this 5G initiatives AI (Artificial Intelligence) and diagnostic of the COVID-19 patients and treated them more efficiently and smartly (Ankel 2020; Tan 2020). (Figs. 1 and 2)

\section{Chinese containment during second COVID-19 wave}

China is the largest and strongest emerging economy in the world. Public and policy experts always in search of making public services more convenient and accessible.
This struggling, support, and innovation from the public and private sectors helped China eliminate poverty from the country and the way forward to sustainable development (CNCDRR 2020; CBI 2020). At the end of 2019, China aimed to launch $6 \mathrm{G}$ (Sixth/ $6^{\text {th }}$ Generation) technology, which will enhance the technology sector and assist in advancing China's healthcare system (Kharpal 2019). The second wave of COVID-19 has hit China in September 2020 (based on COVID-19 cases pattern and tighten again the state containment measures Figs. 3 and 4 will demonstrate in later part of this discussion), although its effect is much lesser than the first wave. China has introduced the 6G technology officially, and the results are significant. It will help reduce $5 \mathrm{G}$ technology concerns via mobile health apps with more efficient services (Wu et al. 2020). This innovation advances healthcare diagnostics in hospitals and medical centers and mitigates human errors. As per the expert,

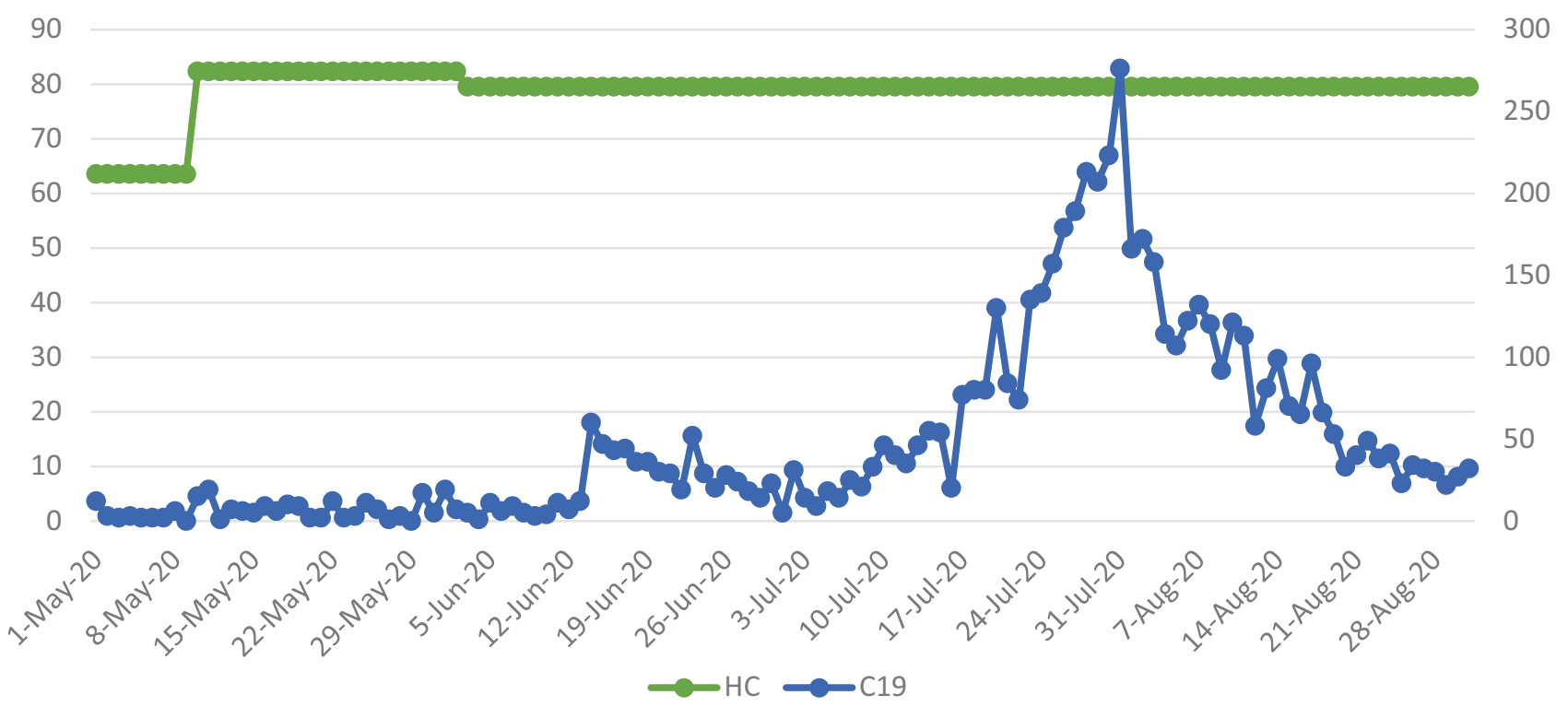

Fig. 2 HC and COVID-19 situation during the Second phase of COVID-19 in China. Source: Hale et al. 2020 and Humanitarian Data Exchange 2020 


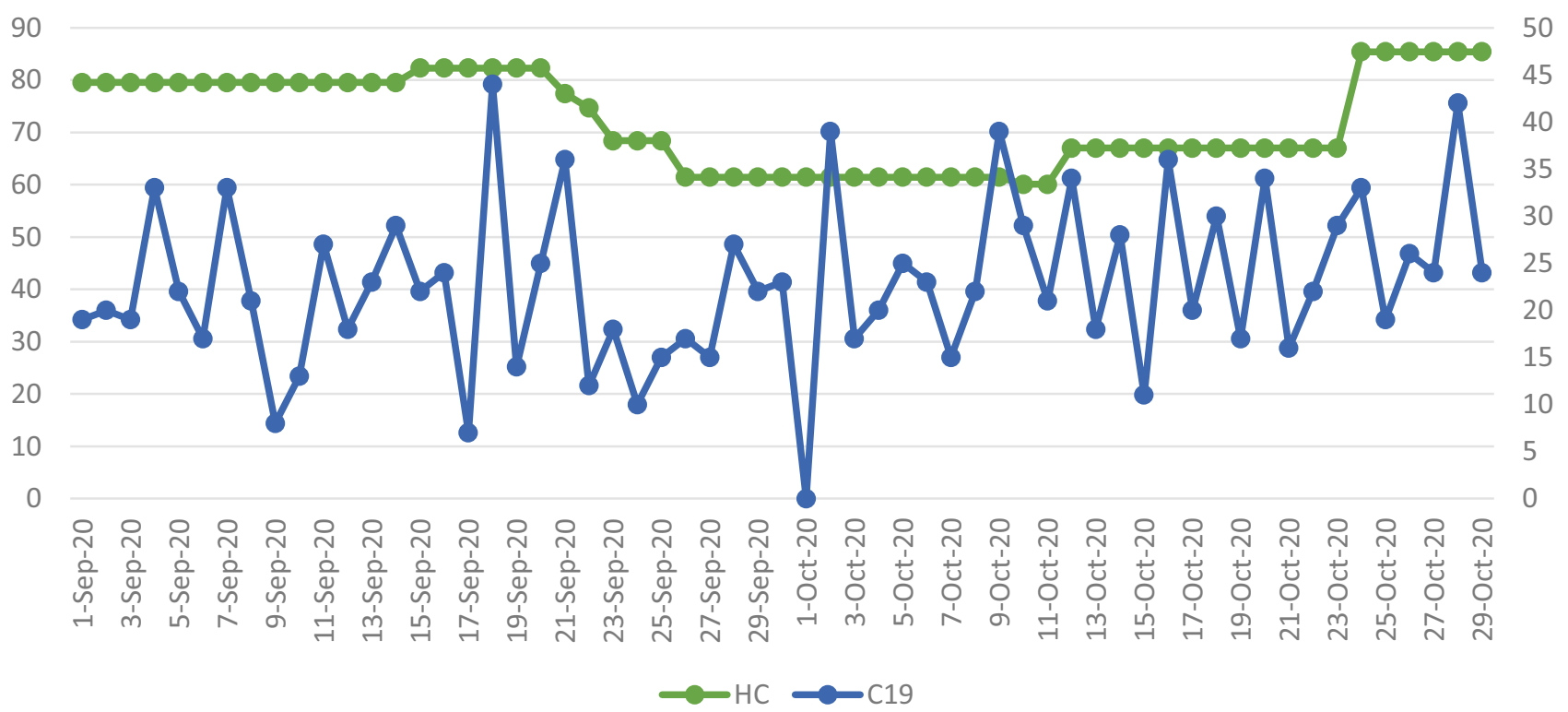

Fig. 3 HC and C19 situation during the Third phase of COVID-19 in China. Source: Hale et al. 2020 and Humanitarian Data Exchange 2020

$6 \mathrm{G}$ is 100 times faster than $5 \mathrm{G}$ and make the industry more robotics and error-free (Lamb 2020).

\section{Containment measures and COVID-19}

This study made four phase-wise analyses and discussion by applying the regression analysis of Health Containment (HC/hc) measures on China's COVID-19 situation.
In the first phase, HC and COVID-19 nexus from January to April; secondly, May to August; thirdly September to October and in the last part, nexus of Health Containment (HC), Stringency Response (SR/sr) measures, and COVID-19 (C19/c19) from January to date has discussed. This analysis tells us that how Chinese initials emergency $\mathrm{HC}$ measures remained sustainable and consistent in combating COVID-19, and in the Long run, stringency measures support the government in enforcing

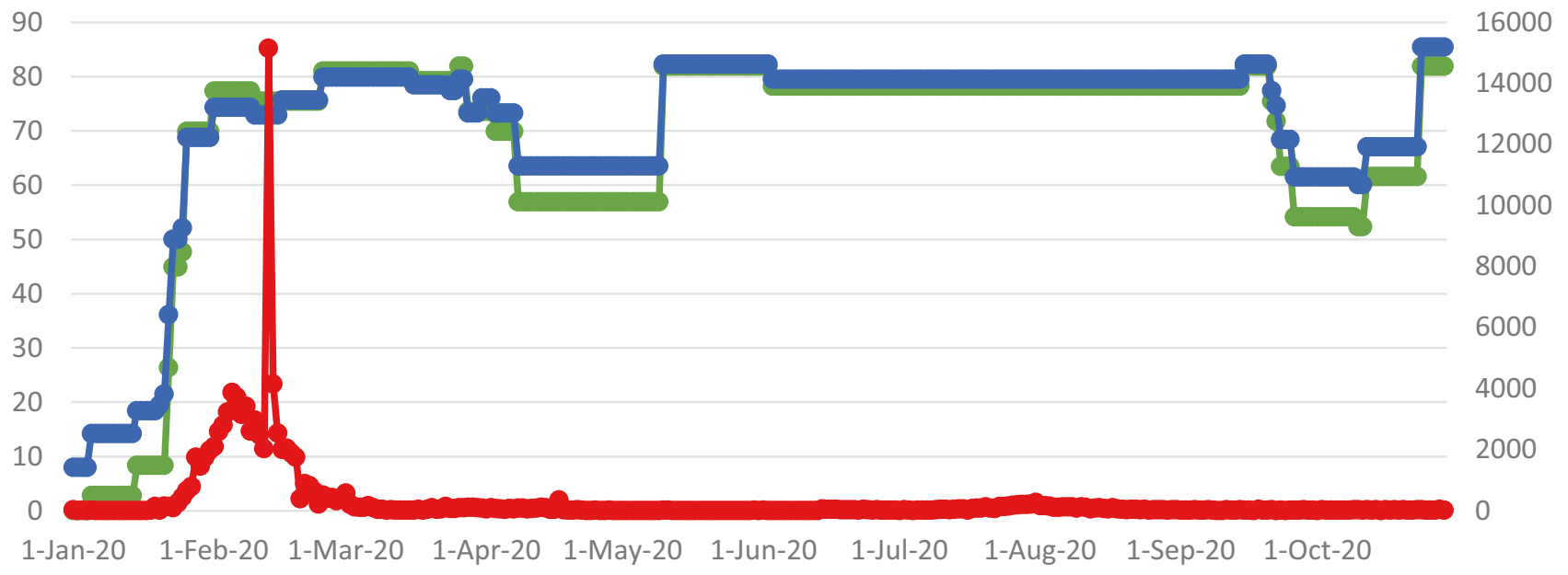

Fig. 4 HC, SR, and COVID-19 situation during Complete Phase of COVID-19 in China so far. Source: Hale et al. 2020 and Humanitarian Data Exchange 2020 
Table $1 \mathrm{HC}$ and $\mathrm{C} 19$

Regression during first phase of COVID-19 in China. Source:

Author Estimation

\begin{tabular}{|c|c|c|c|c|c|c|}
\hline Source & SS & df & MS & Number of obs & $=$ & 121 \\
\hline & & & & $\mathrm{F}(1,119)$ & $=$ & 4.94 \\
\hline Model & 13272649.1 & 1 & 13272649.1 & Prob $>$ F & $=$ & 0.0281 \\
\hline \multirow[t]{2}{*}{ Residual } & 319691163 & 119 & 2686480.37 & $\mathrm{R}$ - squared & $=$ & 0.0399 \\
\hline & & & & Adj R - squared & $=$ & 0.0318 \\
\hline Total & 332963813 & 120 & 2774698.44 & Root MSE & $=$ & 1639 \\
\hline c19 & Coef. & Std. Err. & $\mathrm{t}$ & $\mathrm{P}>|\mathrm{t}|$ & [95\% Conf. & Interval] \\
\hline hc & 14.42034 & 6. 487666 & 2.22 & 0.028 & 1.574112 & 27.26657 \\
\hline _cons & -201.2624 & 429.3493 & -0.47 & 0.64 & -1051.417 & 648.8921 \\
\hline
\end{tabular}

the policies and make them rational in decision-making. Based on COVID-19 data and pattern, this study has hypothesized that the second wave has observed in September 2020.

\subsection{First phase}

The first scenario observed that $\mathrm{HC}$ measures have a 95\% significant impact on COVID-19 in China from January to April. Until February 2020, China had optimum utilized its health containment measures in tackling the COVID-19 situation, which made the COVID-19 graph flatten for the rest of the period while $\mathrm{HC}$ measures were strict at a high degree. In that time, China has operationalized the 5G technology and BIM technology in building makeshift hospitals, medical diagnostics, Health Code applications, and other health care diagnostics measures. (Table 1)

\subsection{Second phase}

From May to August, it was observed that HC measures remained insignificant to COVID-19. A sudden spike was observed at the end of July 2020, when China lifted the international travelers' restriction to a limited extent, relaxed its lockdown policies, and allowed the public to move about the country. However, on-time and the immediate situation seemed under control, which happened due to aggressive and sustainable $\mathrm{HC}$ measures and public awareness developed during the first phase or at the initial days of COVID-19 in China. (Table 2)

\subsection{Third phase}

From September to October 2020, China has further relaxed its health professionals and stringency measures, which again spike the cases during this period. However, near October, China has again enforced its strict health containment measures, which will decrease the COVID-19 graph. Insignificant regression results depict that other than HC, some factors hike the COVID-19 situation in China while HC measures have controlled and slowed down the pandemic. (Table 3)

\subsection{Complete phase}

A complete analysis has been done from January to October 2020. The analysis shows that in the long run, mere HC has not been working in China during a pandemic; the aggressive and strict stringency measures also support combating COVID-19. Both HC and stringency are $99 \%$ significant in combating COVID-19 in China so far. In the long run, the Chinese government's HC and SR
Table 2 HC and COVID-19 Linear Regression during Second phase of COVID-19 in China. Source: Author Estimation

\begin{tabular}{lllllll}
\hline Source & SS & df & MS & Number of obs & $=$ & 123 \\
\hline & & & & F $(1,121)$ & $=$ & 1.76 \\
Model & 5657.21565 & 1 & 5657.21565 & Prob $>$ F & $=$ & 0.1866 \\
Residual & 387969.825 & 121 & 3206.36219 & R - squared & $=$ & 0.0144 \\
& & & & Adj R - squared & $=$ & 0.0062 \\
Total & 393627.041 & 122 & 3226.45115 & Root MSE & $=$ & 56.625 \\
c19 & Coef. & Std. Err. & t & P >ltl & {$[95 \%$ Conf. } & Interval] \\
hc & 1.524976 & 1.148069 & 1.33 & 0.187 & -0.74793 & 3.797881 \\
ccons & -71.91394 & 90.70795 & -0.79 & 0.429 & -251.4943 & 107.6664 \\
\hline
\end{tabular}


Table $3 \mathrm{HC}$ and COVID-19 Linear Regression during Third phase of COVID-19 in China. Source: Author Estimation

\begin{tabular}{|c|c|c|c|c|c|c|}
\hline Source & SS & df & MS & Number of obs & $=$ & 59 \\
\hline & & & & $\mathrm{F}(1,57)$ & $=$ & 0.46 \\
\hline Model & 36.7871713 & 1 & 36.7871713 & Prob $>$ F & $=$ & 0.5005 \\
\hline \multirow[t]{2}{*}{ Residual } & 4562.16198 & 57 & 80.0379295 & $\mathrm{R}$ - squared & $=$ & 0.008 \\
\hline & & & & Adj R - squared & $=$ & -0.0094 \\
\hline Total & 4598.94915 & 58 & 79.2922268 & Root MSE & $=$ & 8.9464 \\
\hline c19 & Coef. & Std. Err. & $\mathrm{t}$ & $\mathrm{P}>|\mathrm{t}|$ & [95\% Conf. & Interval] \\
\hline hc & 0.0883151 & 0.1302671 & 0.68 & 0.501 & -0.17254 & 0.3491705 \\
\hline _cons & 16.43484 & 9.48059 & 1.73 & 0.088 & -2.54971 & 35.4194 \\
\hline
\end{tabular}

Table 4 HC, SR and COVID19 Linear Regression during Complete phase of COVID19 in China. Source: Author Estimation

\begin{tabular}{|c|c|c|c|c|c|c|}
\hline Source & SS & $\mathrm{DF}$ & MS & Number of Obs. & & 303 \\
\hline & & & & $\mathrm{F}(2,300)$ & & 41.54 \\
\hline Model & 79033991.6 & 2 & 39516995.8 & Prob. > & & 0 \\
\hline \multirow[t]{2}{*}{ Residual } & 285408016 & 300 & 951360.052 & R-squared & & 0.2169 \\
\hline & & & & Adj. R-squared & & 0.2116 \\
\hline Total & 364442007 & 302 & 1206761.61 & Root MSE & & 975.38 \\
\hline C19 & Coeff. & Std. Err. & $\mathrm{t}$ & $\mathrm{P}>|\mathrm{t}|$ & [95\% Conf. & Interval] \\
\hline SRI & 239.2479 & 26.35335 & 9.08 & 0.000 & 187.3871 & 291.1088 \\
\hline $\mathrm{HCI}$ & -276.4297 & 30.91636 & -8.94 & 0.000 & -337.2701 & -215.589 \\
\hline Constant & 3537.554 & 446.6897 & 7.92 & 0.000 & 2658.512 & 4416.596 \\
\hline
\end{tabular}

measures have been sustainable and effective. The effectiveness of Chinese policy implications can be observed through the progress and resumption of china's economy (Xinhua 2020; Bloomberg 2020; Hubei Provincial People's Government 2020; Sengyee 2020). (Table 4)

The rest of the world focuses on lockdown and partial lockdown again in protecting the second or coming projected waves of COVID-19; China is boosting and expanding its economy (Ankel 2020; Shim et al. 2020). Chinese 5G technology operations, Health smart application, and communication in tracing, diagnostic, sharing, and informative features played a vital role in Chinese containment policies during pandemics (Bradford et al. 2020; Wu et al. 2020). 5G and AI deployment assist the health professionals and practitioners in treating COVID-19 patients and online high-resolution video diagnostic expertise as a distance learning (Tan 2020; Smith; 2020; Hasan 2020 Leins et al. 2020). China's technology deployment during the COVID-19 pandemic made a vital contribution to sustainable E-government development that supports the government in controlling the situation much effectively compared to the rest of the world (Ullah et al. 2020).

\section{Conclusion}

China's technology innovation and policy measures have set a global illustration of emergency management in controlling pandemic. After China, Australia, and the US started health applications to collect and communicate the citizens' information. European and other developed states are taking continuous assistance from China concerning COVID-19. China exports its advanced Medical technology and sends its experts to struggling countries of Asia and Africa. At the same time, China jointly works in vaccine development with WHO aggressively. By including 6G technology, China will lead the world at the next healthcare treatment level and make this noble profession error-free.

This study has discussed the Chinese Health and Stringency measures during the COVID-19 pandemic in various phases in the background of $5 \mathrm{G}$ and $6 \mathrm{G}$ technology. However, very little or rare explanation and literature available on 6G deployment in China will be explored and investigated in some future studies. For future study, health technology stringency measures and COVID-19 smartphone application's role will be an excellent and trending research area in China and other regional countries. 
Acknowledgement We thank Professor Dr. Qais Aslam, School of Management Studies and Head of Department, University of Central Punjab, Lahore Pakistan on reviewed the paper and improved the language through their expertise on priority basis. He can be contacted through (dr.qais@ucp.edu.pk) and viewed from (https://www.ucp.edu. pk/member/prof-dr-qais-aslam/).

\section{Compliance with ethical standards}

Conflict of interest The authors declare that they have no conflict of interest.

\section{References}

Ashraf BN. Socioeconomic conditions, government interventions and health outcomes during COVID-19. Covid Economics. 2020;37:141-62.

Ankel S. As China lifts its coronavirus lockdowns, authorities are using a color-coded health system to dictate where citizens can go. Here's how it works. Tech [Online]. 2020. Available from: https:// www.businessinsider.com/coronavirus-china-health-softwarecolor-coded-how-it-works-2020-4. Accessed 07 April 2020.

Bloomberg. China to Lift Lockdown Over Virus Epicenter Wuhan, 2020. Available: https://www.bloomberg.com/news/articles/202003-24/china-to-lift-lockdown-over-virus-epicenter-wuhanon-april-8.

Bradford LR, Aboy M, Liddell K. COVID-19 Contact Tracing Apps: A Stress Test for Privacy, the GDPR and Data Protection Regimes. J Law Biosci. 2020.

Brende, B., \& Morhard, R. (2020). A New York simulation showed we weren't prepared for coronavirus. But it's not too late to act. The World Economic Forum COVID Action Platform. Retrieved from weform.org website: https://www.weforum.org/agenda/ 2020/03/covid-19-coronavirus-newyork-simulation-lessonsnot-too-late-to-act/.

CBI. Lessons learnt from China. 2020. Available: https:/www.cbi.org.uk/articles/ covid-19-lessons-learnt-from-china/.

CNCDRR. Foundation Disaster Relief Coordination Meeting. 2020. Available: https://mp.weixin.qq.com/s?_biz=MzA3MzA5NT $\mathrm{c} 4 \mathrm{MA}==\& \mathrm{mid}=2687798741 \& \mathrm{idx}=1 \& \mathrm{sn}=1273 \mathrm{dde} 40 \mathrm{ec} 9 \mathrm{c} 6 \mathrm{a}$ 942a76ac07a478a31\&chksm =bad462de8da3ebc8428d3f7b2f086e 8b3c5aa0487c35d4aa9c682aa8493f97a640b6050bbb45\&mpsha

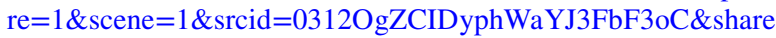
r_sharetime.

Hale T, Petherick A, Phillips T, Webster S. Variation in government responses to COVID-19. 2020. Blavatnik school of government working paper, 31

Hasan N. A Methodological Approach for Predicting COVID-19 Epidemic Using EEMD-ANN Hybrid Model. 2020. Internet of Things, 100228.

Hubei Provincial People's Government. Update information on the novel coronavirus in Hubei on April 8, 2020. In: OFFICE., H. P. F. A. (ed.). Wuhan, China: General Office of Hubei Provincial People's Government. 2020.

Humanitarian Data Exchange. (2020). Novel Coronavirus (COVID19) Cases Data (Live Updates). Retrieved 17-11-2020, from Humanitarian Data Exchange https://data.humdata.org/dataset/ novel-coronavirus-2019-ncov-cases.
International Monetary Fund. Policy responses to COVID-19. 2020. Available: https://www.imf.org/en/Topics/imf-and-covid19/ Policy-Responses-to-COVID-19.

Kharpal, A. (2019). China starts development of 6G, having just turned on its $5 \mathrm{G}$ mobile network. Tech. Retrieved from: https://www.cnbc. com/2019/11/07/china-starts-6g-development-having-just-turned-onits-5g-mobile-network.html.

Lamb K. 6G: A case for why China will become more innovative. Opinion [Online]. 2020. Available: https://news.cgtn.com/ news/2020-11-12/6G-A-case-for-why-China-will-become-moreinnovative-VkZEUtnFgA/index.html.

Leins K, Culnane C, Rubinstein BI. Tracking, tracing, trust: contemplating mitigating the impact of COVID-19 through technological interventions. Med J Aus. 2020. 1.

Maragakis LL. Coronavirus Second Wave? Why Cases Increase. Health \& Place [Online]. 2020. Available: https://www.hopkinsmedicine. org/health/conditions-and-diseases/coronavirus/first-and-secondwaves-of-coronavirus.

National Health Commission, China. Wuhan's makeshift hospitals close after last patients are discharged. In: COMMISION, T. G. O. P. R. C. N. H. (ed.). Beijing, China: ChinaDaily. 2020.

Sengyee L. How China's industrial internet is fighting COVID-19. Worl Economic Forum, 2020.

Shim E, Tariq A, Choi W, Lee Y, Chowell G. Transmission potential and severity of COVID-19 in South Korea. Int J Infect Dis. 2020.

Smith M. How China's health code app is used to fight infection. 2020. Available: https://www.afr.com/world/asia/how-china-s-health-codeapp-is-used-to-fight-infection-20200424-p54mzk.

Tan S. China's Novel Health Tracker: Green on Public Health, Red on Data Surveillance. Trustee China Hand [Online]. 2020. Available from: https://www.csis.org/blogs/trustee-china-hand/chinasnovel-health-tracker-green-public-health-red-data-surveillance. Accessed 04 May 2020.

The State Council of China. Fighting Covid-19 China in Action. In: CHINA, T. S. C. I. O. O. T. P. S. R. O. (ed.). Beijing, China: Government of PR China. 2020.

Ullah A, Pinglu C, Ullah S, Abbas HSM, Khan S. The Role of E-Governance in Combating COVID-19 and Promoting Sustainable Development: A Comparative Study of China and Pakistan. Chinese Political Science Review. 2020. 1-33.

World Economic Forum. Fourth Industrial Revolution. 2020. Available: https://www.wefor um.org/agenda/2020/05/how-the-fourthindustrial-revolution-can-help-us-handle-the-threat-of-covid-19/.

World Health Oganization. Coronavirus disease (COVID-19) Weekly Epidemiological Update and Weekly Operational Update. 2020.\& Weekly operational update on COVID-19. 30 October 2020.

Wu X, Xu X, Wang X. 6 lessons from China's Zhejiang Province and Hangzhou on how countries can prevent and rebound from an epidemic like COVID-19. The World Economic Forum COVID Action Platform [Online]. 2020. Available: https://www.weforum. org/agenda/2020/03/coronavirus-covid-19-hangzhou-zhejianggovernment-response/.

Xinhua. Xi Focus: With virus basically curbed, China pushes ahead battle against economic fallout. 2020. In: HUAXIA (ed.). Beijing, China: xinhuanet. 